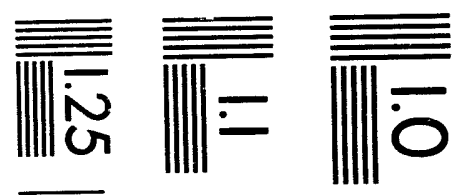

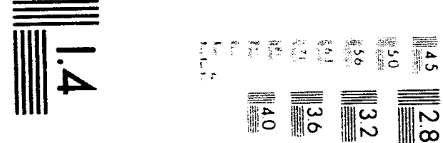

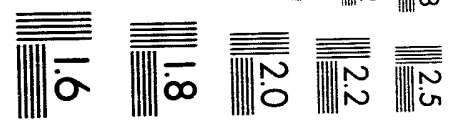



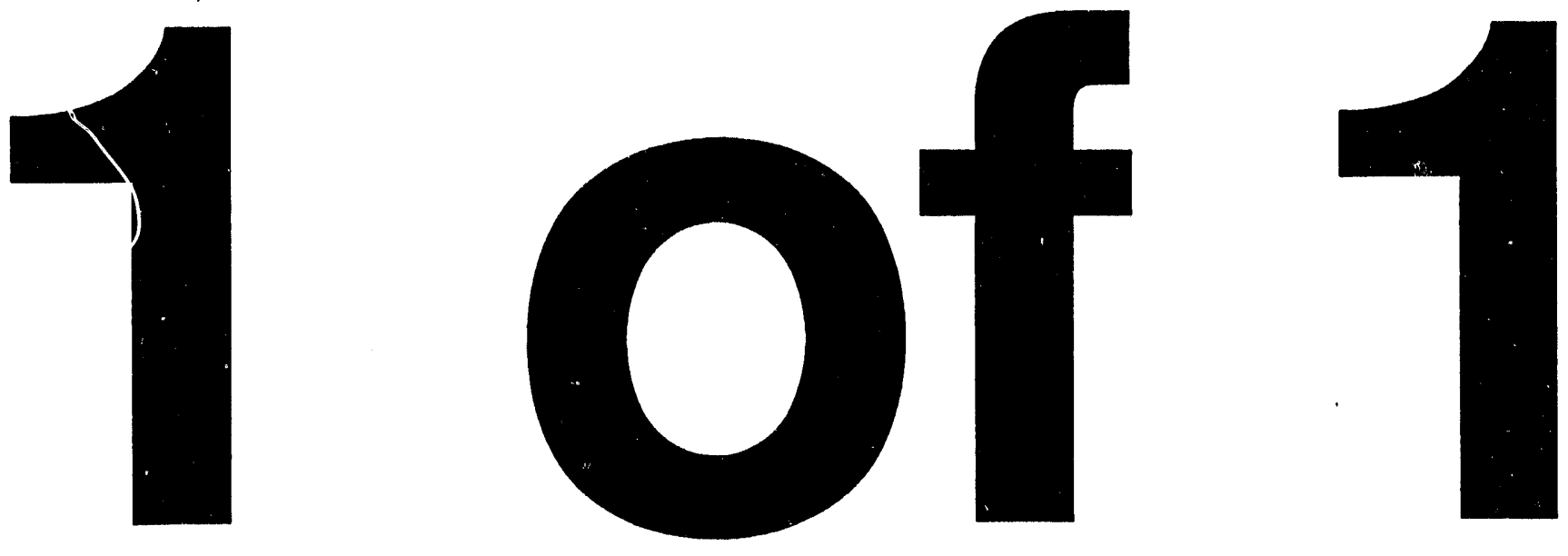


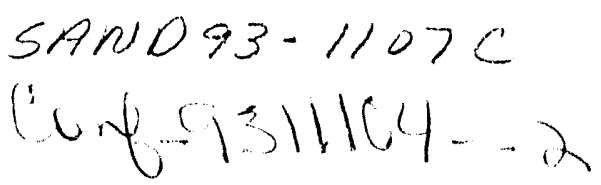

\title{
Ultraviolet Photosulfidation of III-V Compound Semiconductors for Electronic Passivation
}

Kevin R. Zavadil, Carol I. H. Ashby, Arnold J. Howard, and B. E. "Gene" Hammons

Sandia National Laboratories, Albuquerque, New Mexico 87185

\begin{abstract}
A new vacuum-compatible passivation technique for III-V compound semiconductors has been developed. Sulfur passivation of $\mathrm{GaAs}(100)$ is produced by ultraviolet photolytic deposition of a sulfide species from vapor phase elemental sulfur. Photoluminescence studies of the photosulfided GaAs reveal a degree of passivation greater than or equal to that produced by conventional $\left(\mathrm{NH}_{4}\right)_{2} \mathrm{~S}$ solution treatments. X-ray Photoelectron Spectroscopy has shown that the sulfur resides on the surface as a single reduced sulfur species, either as sulfide of disulfide, indicating complete fragmentation of the $\mathrm{S} 8$ ring by UV light in proximity to the surface. The degree of photosulfidation depends strongly on surface preparation as demonstrated by the described surface oxide removal studies.
\end{abstract}

\section{Introduction}

The performance of III-V compound semiconductor devices is often limited by the high density of mid-gap states that exist at the unpassivated semiconductor surface. Reduction of the number of electronically deleterious surface states could improve the operation of heterojunction bipolar transistors (HBTs), nonvolatile memories, and metalinsulator field-effect transistors (MISFETs). Additionally, the Fermi-level unpinning that would result from reduction of surface state density would produce improved Schottky 


\section{DISCLAIMER}

This report was prepared as an account of work sponsored by an agency of the United States Government. Neither the United States Government nor any agency thereof, nor any of their employees, makes any warranty, express or implied, or assumes any legal liability or responsibility for the accuracy, completeness, or usefulness of any information, apparatus, product, or process disclosed, or represents that its use would not infringe privately owned rights. Reference herein to any specific commercial product, process, or service by trade name, trademark, manufacturer, or otherwise does not necessarily constitute or imply its endorsement, recommendation, or favoring by the United States Government or any agency thereof. The views and opinions of authors expressed herein do not necessarily state or reflect those of the United States Government or any agency thereof. 
contacts. Consequently, there is great need for surface passivation techniques that ameliorate the problems of high surface recombination velocities and Fermi-level pinning by changing the dominant surface electronic states.

Reaction with sulfur can reduce the surface states that promote rapid OCT 221993 recombination and Fermi-level pinning (1-10). Aqueous and alcoholic sulfide-based OSTI solutions have been extensively studied(1-6). However, these processes possess the inherent disadvantages of wet processing combined with odorous solutions that release toxic hydrogen sulfide, $\mathrm{H}_{2} \mathrm{~S}$.

The use of $\mathrm{H}_{2} \mathrm{~S}$ activated by a hot filament (9) or in a plasma (10) has been proposed as an alternative dry process. However, a hydrogen-containing sulfur source can result in subsurface penetration of hydrogen, passivation of bulk donors and/or acceptors, and an unacceptable reduction in free carrier concentrations (11). Thermal annealing to remove hydrogen will restore dopant activity, but this treatment is sufficient to also remove sulfur (11-14), thereby destroying the surface passivation. In addition, plasmabased processes can expose the surface to ion bombardment, resulting in damage that can exacerbate the carrier recombination problem. Avoidance of these problems requires a dry process for surface sulfidation that both avoids ion bombardment and uses no hydrogenic sources.

We have developed a new dry process for III-V surface passivation based on ultraviolet photolysis of elemental sulfur (15). In the present paper, we report the improved efficacy of photosulfidation as a passivant for GaAs, but, like other sulfur treatments, our process should also improve surface properties of other III-V compound semiconductors (14).

\section{Experiment}


Sulfur passivation studies were conducted with $\mathrm{n}-\mathrm{GaAs}\left(6.9 \times 10^{16} / \mathrm{cm}^{3}\right)$ and $\mathrm{p}$ GaAs $\left(1.1 \times 10^{17} / \mathrm{cm}^{3}\right)$ grown by molecular beam epitaxy (MBE) on a substrate of (100) $\mathrm{n}^{+}-$GaAs $\left(1.85 \times 10^{18} / \mathrm{cm}^{3}\right)$. Substrate material was used for completing the survey of suitable methods of native oxide removal from the GaAs surface. Failure to remove the native oxide effectively precludes any photosulfidation. Two common etchant solutions, 1:20 $\mathrm{NH} 4 \mathrm{OH} / \mathrm{H}_{2} \mathrm{O} /$ and 1:10 HCl/ethanol, were used for oxide removal. The GaAs surface was flushed with the etchant for 30 seconds and, in the case of the $\mathrm{HCl} / \mathrm{ethanol}$ etchant, rinsed in ethanol. Electronic grade reagents were used to prepare the etchant solutions. Because the prototype sulfur deposition chamber was not designed for in-situ oxide removal, the degree to which the surface is oxide free, and hence the subsequent degree of photosulfide passivation, is strongly dependent on sample handling between removal from the oxide etchant solutions and sulfur exposure in-vacuo. Our original cleaning studies were conducted in the ambient atmosphere under copious $\mathrm{N}_{2}$-gas flow to blow-dry the substrate after etching/rinsing and to provide a relatively inert gas curtain for vacuum loading (15). Excessive oxygen exposure during such handling has led us more recently to use $\mathrm{N}_{2}$-purged glove bags attached to our photodeposition and analysis chambers for cleaning and loading processes.

The photodeposition chamber is a standard high vacuum cross equipped with a $\mathrm{MgF}_{2}$ viewport, low current/thermocouple feedthrough, a custom sample mount and appropriate valving for turbomolecular pumping, isolation and inert gas backfilling. The sulfur source consists of a glass crucible containing precipitated sulfur powder $(>99.5 \%)$. The sulfur temperature and vapor pressure can be controlled by resistively heating a wire element wrapped about the crucible. The source temperature is monitored with a thermocouple attached to the crucible with a thermally conductive ceramic adhesive Typical source temperatures during deposition are $46-48^{\circ} \mathrm{C}$, which yields a sulfur partial 
pressure of $3 \times 10^{-5}$ Torr (16). Photodissociation of the $S_{8}$ allotrope to produce highly reactive sulfur radicals is accomplished by irradiation with UV light $(\lambda<320 \mathrm{~nm})(17)$. A high pressure $\mathrm{Hg}$ arc lamp was used as a UV photon source. We estimate a photon flux for $\lambda<320 \mathrm{~nm}$ to be $2-4 \times 10^{15}$ photons $/ \mathrm{cm}^{2}$-s. Under deposition conditions, we estimate a photon-to-S 8 flux ratio of $2: 1$ at the GaAs surface.

It is esse:tial that the surface be illuminated before it is exposed to significant sulfur vapor pressures since no appreciable reaction occurs between the GaAs surface and the photoactivated sulfur if the surface is exposed to $10^{-5}$ Torr sulfur before illumination. We attribute this lack of reaction to deposition of a sufficient thickness of sulfur on the surface to exclude access to the GaAs of photodissociated reactive sulfur species. Photolytic formation of highly reactive sulfur species may occur in the gas phase or during adsorption on the GaAs surface; our experiments to date do not exclude either possibility.

The intensity of the room temperature GaAs PL signal at a fixed wavelength of $872-\mathrm{nm}$ with a spectrometer band pass of $8 \mathrm{~nm}$ was used to assess the effecijiveness of photosulfidation as a surface passivant. Most S-based passivations are unstable in the presence of oxygen; this instability is increased in the presence light. Consequently, a $\mathrm{N}_{2}$ gas curtain was maintained across the sample surface to minimize oxygen exposure during PL measurements. The PL excitation intensity at $488 \mathrm{~nm}$ was held constant at less than 3.6 $\mathrm{W} / \mathrm{cm}^{2}$ for all PL reported here. The PL intensity was measured at 9.25 second intervals with a lock-in time constant of $3 \mathrm{sec}$. Although these conditions result in moderate signal to noise, they minimize photo-induced loss of passivation due to the PL-excitation beam. The variation in the values for PL intensity from native oxide surfaces is less than 0.05 arbitrary units as displayed in Fig. 1; we assume a similar measurement uncertainty for sulfided surfaces. The PL intensity from samples immersed in aqueous $\left(\mathrm{NH}_{4}\right)_{2} \mathrm{~S}$ for 15 
min at $21^{\circ} \mathrm{C}$, a common wet sulfide process, was also measured for comparison of the conventional wet process with photosulfidation.

Surface analysis was performed on a VG ESCALAB 5 spectrometer operated at a base pressure of $2 \times 10^{-10}$ Torr. Core level spectra were obtained using a $300 \mathrm{~W} \mathrm{Al}(\mathrm{K} \alpha)$ source and operating the hemispherical analyzer in a constant energy mode at a pass energy of $20 \mathrm{eV}$. Energy axis calibration was performed to obtain positions for the $\mathrm{Au}(4 \mathrm{f} 7 / 2), \operatorname{Au}\left(\mathrm{M}_{5} \mathrm{~N}_{6,7} \mathrm{~N}_{6,7}\right)$, and $\mathrm{Cu}\left(2 \mathrm{p}_{3 / 2}\right)$ transitions of $84.0 \mathrm{eV}(\mathrm{BE}), 2015.1 \mathrm{eV}$ $(\mathrm{KE})$, and $932.6 \mathrm{eV}(\mathrm{BE})$, respectively.

\section{Results and Discussion}

\section{Surface oxide removal:}

Because the efficient removal of oxygen from the GaAs surface is essential for maximum photosulfidation and passivation, we will first discuss the results of our studies of surface oxide removal. using either irrigation with a $1: 20 \mathrm{NH} 4 \mathrm{OH} / \mathrm{H}_{2} \mathrm{O}$ solution or irrigation with a $1: 10 \mathrm{HCl} /$ ethanol solution followed by rinsing with ethanol (18). The removal of part or all of the native oxide from the GaAs surface results in an increase in the PL intensity. However, this increase resulting from sinple oxide removal is at least a factor of two less than the PL increase resulting from photosulfidation following $\mathrm{NH}_{4} \mathrm{OHI}$ cleaning in air, which is the least effective of our photosulfidation process protocols. Meaningful comparison of PL improvements resulting from various cleaning techniques is not possible because of the excessive reactivity of these surfaces toward oxygen if the surface is not protected by sulfur.

Figure 2 compares the $\operatorname{As}\left(2 \mathrm{p}_{3 / 2}\right)$ spectrum of the $\mathrm{n}^{+}-\mathrm{GaAs}\left(1 \times 10^{18} / \mathrm{cm}^{3}\right)$ surface covered with native oxide and the spectrum of the surface after cleaning with $\mathrm{NH}_{4} \mathrm{OH}$ or 
$\mathrm{HCl} /$ ethanol in a $\mathrm{N}_{2}$-purged glove bag. The spectrum acquired for the native oxide shows a narrow, low energy component at $1323.3 \mathrm{eV}$ due to zero-valent As characteristic of GaAs and a broad, high energy component at $1327.0 \mathrm{eV}$ due to oxidized As. Cleaning with either reagent results in virtual elimination of the oxidized component and restoration of intensity for the zero-valent component. Analogous changes are observed in the $\mathrm{Ga}(2 \mathrm{p} 3 / 2)$ spectra with oxide removal. The native oxide shows two features at 1117.4 and $1118.7 \mathrm{eV}$ corresponding to $\mathrm{Ga}^{\circ}$ and $\mathrm{Ga}^{\mathrm{n}}{ }^{+}(\mathrm{n}=1-3)$, respectively. Oxide etching yields only the transition for zero-valent $\mathrm{Ga}$.

The loss of the surface oxide may also be tracked by monitoring the $O(1 \mathrm{~s})$ transition at approximately $531 \mathrm{eV}$ (not shown). This transition is most effectively monitored by using a $\operatorname{Mg}(\mathrm{K} \alpha)$ source due to spectral interference from the photoninduced $\mathrm{Ga}(\mathrm{LMM})$ Auger series. Removal of the native oxide with $\mathrm{NH}_{4} \mathrm{OH}$ produces an eight-fold decrease in the $\mathrm{O}(\mathrm{ls})$ signal while pretreatment with $\mathrm{HCl} /$ ethanol yields a fourteen-fold decrease. These decreases produce a final surface oxygen concentration of approximately 7 and 4 atomic $\%$, respectively. The fact that an oxygen signal remains after treatment indicates either that these reagents leave residual oxide on the surface or that readsorption of $\mathrm{O}_{2}$ is rapid, even with the reduced partial pressure of $\mathrm{O}_{2}$ in the $\mathrm{N}_{2}$ atmosphere. We have previously found that substrates cleaned in the ambient atmosphere (with and without copious $\mathrm{N}_{2}$ flow) display typically two-to-three times larger residual oxide signals than their counterparts cleaned in a glove bag. Pretreatment with $\mathrm{NH}_{4} \mathrm{OH}$ yields the largest residual values. It is difficult to lower the surface oxygen signal much below 10 at. \% using an aqueous-based etchant in the laboratory ambient. We believe that this poorer performance of the aqueous $\mathrm{NH}_{4} \mathrm{OH}$ may be due to the water solvent; the hydrophobic surface generated by oxide removal repels the solution and leaves the surface exposed for $\mathrm{O}_{2}$ re-adsorption. Ethanol continues to wet the surface after oxide removal, producing an apparent diffusion barrier to $\mathrm{O}_{2}$ in the ambient environment. The 
improvement in surface oxygen removal for both solutions in the inert atmosphere is a clear indication that $\mathrm{O}_{2}$ re-adsorption contributes to residual surface oxygen following either pretreatment.

Residual surface carbon and chlorine are the potential disadvantages of using the $\mathrm{HCl} /$ ethanol etchant. The native oxide and $\mathrm{NH} 4 \mathrm{OH}$-etched surfaces show no discernible trace of either of these contaminants. $\mathrm{HCl}$-etched surfaces generally do not yield a detectable $\mathrm{Cl}(2 \mathrm{p})$ signal when copiously rinsed in ethanol. However, the cross-section for $\mathrm{Cl}(2 \mathrm{p})$ photoemission is very low (19) and a reasonable estimate of the lower limit of detection of 1 at. \% makes trace levels of $\mathrm{Cl}$ difficult to observe. Carbon shows up quite readily on $\mathrm{HCl}$-treated surfaces (6 at. \%) and appears to be endemic with the use of inorganic acids (20). This combination of residual surfaces contaminants on $\mathrm{NH} 4 \mathrm{OH}$ - and $\mathrm{HCl} /$ ethanol-cleaned $\mathrm{GaAs}(100)$ appears to be responsible for the lack of a coherent low energy electron diffraction (LEED) pattern for $50 \mathrm{-to} 150 \mathrm{-eV}$ electrons.

The selection of a basic or acidic etch for the surface appears to have minimal impact on the surface stoichiometry. Computation of $\mathrm{Ga} / \mathrm{As}$ ratios based on the $2 \mathrm{p} 3 / 2$ transitions yields values of 0.99 and 0.93 for the $\mathrm{NH} 4 \mathrm{OH}$ and $\mathrm{HCl}$ treatments, respectively. These values are within the relative standard deviation of $8 \%$ found for measurements on multiple samples. The previously reported phenomenon of surface enrichment of As with acid treatment (21) is not observed in our work.

\section{Photosulfidation:}

The effect of various surface preparation techniques on the increase in PL intensity are shown in Fig. 1 for $6.9 \times 10^{16} / \mathrm{cm}^{3} \mathrm{n}$-GaAs. An increase in PL intensity is indicative of a change in the relative proportions of radiative and nonradiative recombination as the surface states are altered by sulfur addition. Handling in the low-oxygen $\mathrm{N}_{2}$ glove bag 
appears to reduce surface reoxidation, permitting a greater degree of photosulfidation and, therefore, a greater PL intensity increase. Indeed, photosulfidation of a well-cleaned surface produces significantly greater PL improvement than that resulting from the wellestablished $\left(\mathrm{NH}_{4}\right)_{2} \mathrm{~S}$ dip process.

The importance of careful oxygen exclusion is emphasized by the $\mathrm{N}_{2}$ bag results for the $\mathrm{HCl} /$ ethanol clean. Operation in the bag with an extra source of flowing $\mathrm{N}_{2}$ directed at the sample surface at all times produces b) in Fig. 1. In contrast, operation in the bag without this extra oxygen exclusion step produces a). Extremely careful handling outside the $\mathrm{N}_{2}$ bag with aggressive $\mathrm{N}_{2}$ flow on the surface after $\mathrm{HCl}$ /ethanol cleaning has produced PL improvements of 11-12 fold over that of the native oxide (15).

Under the same atmospheric conditions (air vs. $\mathrm{N}_{2}$ glove bag), $\mathrm{HCl} /$ ethanol pretreatment produces a greater increase in the PL intensity following photosulfidation than that obtained with aqueous $\mathrm{NH}_{4} \mathrm{OH}$ cleaning. This may be attributed to the greater re-exposure of the surface to oxygen due the hydrophobicity effect disisussed above. The effect is less pronounced in the $\mathrm{N}_{2}$ bag, where the effect of hydrophobicity in exposing the cleaned surface to oxygen will naturally be less.

Exposure of the GaAs(100) surface to sulfur vapor in the presence of UV light results in sulfur deposition and the appearance of discrete oxidized As and Ga states. Figure 3 shows the $\mathrm{As}\left(2 \mathrm{p}_{3} / 2\right)$ spectra for surfaces pretreated with $\mathrm{NH}_{4} \mathrm{OH}$ and $\mathrm{HCl}$. The zero-valent As transition is visible at $1323.3 \mathrm{eV}$ along with a higher binding energy transition at $1325.1 \mathrm{eV}$. The oxidative shift for this feature is $1.9 \pm 0.1 \mathrm{eV}$; a shift of 3.7 $\mathrm{eV}$ is observed for the oxide. In addition, this product transition is narrower with a FWHM (full width at half maximum) of $1.8 \mathrm{eV}$ compared to the $2.9 \mathrm{eV} \mathrm{FWHM}$ for the oxide. An analogous smaller oxidative shift is observed for the sulfur-associated $\operatorname{As}(3 \mathrm{~d})$ when compared to the shift observed for the oxide. The sulfur-associated oxidative shift of the $\mathrm{Ga}(2 \mathrm{p} 3 / 2)$ is so small that the only indication that sulfur bonding to $\mathrm{Ga}$ has occurred is 
an increase in the FWHM (ca. 12\%) of this transition relative to that of the clean surface. This disparity in the oxidative shifts for core levels of As and Ga has been previously reported for the As and Ga $3 \mathrm{~d}$ core levels for sulfur bonding (8).

Sulfur resides on the $\mathrm{GaAs}(100)$ surface as a single negatively charged species. The presence of reduced sulfur can be demonstrated by monitoring the $S(2 p)$ photoemission induced by the $\mathrm{Al}(\mathrm{K} \alpha)$ source and the $\mathrm{S}\left(\mathrm{KL}_{2,3} \mathrm{~L}_{2,3}\right)$ Auger emission induced by Bremsstrahlung radiation from this source. Figure 4 shows the $S(2 p)$ and $\mathrm{S}\left(\mathrm{KL}_{2,3} \mathrm{~L}_{2,3}\right)$ spectra after photosulfidation of $\mathrm{NH}_{4} \mathrm{OH}$ - and $\mathrm{HCl}$-cleaned surfaces prepared in the $\mathrm{N}_{2}$ bag. Comparison of peak areas for the $S(2 p)$ and $S\left(K_{2,3} L_{2,3}\right)$ transitions shows an approximate $10 \%$ relative increase in the sulfur concentration for the $\mathrm{HCl} / \mathrm{ethanol}$ cleaned surface; concomitantly, greater PL intensities are obtained by photosulfidation following the $\mathrm{HCl} /$ ethanol clean (Fig. 1). Under these conditions, oxygen is present at levels approaching the lower detection limit of our apparatus. Consequently, direct correlation between sulfur and oxygen quantities is not possible.

The $S(2 p)$ and $S(K L L)$ spectra can be used to identify the dominant form of surface sulfur. The $S(2 p)$ spectra are complicated by spectral interference from the $\mathrm{Ga}(3 \mathrm{~s})$ and the bulk plasmon loss from the $\operatorname{As}(3 p)$. However, these spectra clearly show that the predominant form of surface sulfur is a low binding energy species at $161.9 \mathrm{eV}$ (neglecting spin-orbit splitting of the $3 / 2$ and $1 / 2$ states). These spectra also show no evidence of higher oxidation state sulfur, suggesting a lack of elemental sulfur or oxygenated sulfur, as previously reported with $\left(\mathrm{NH}_{4}\right)_{2} \mathrm{~S}$ treatment $(22)$. The $\mathrm{S}\left(\mathrm{KL}_{2}, 3 \mathrm{~L}_{2}, 3\right)$ spectra show a single transition at $2114.7 \mathrm{eV}$ for both methods of surface cleaning. This value lies between the disulfide (2114.3 eV) and sulfide (2115.3 eV) assignments given by Sandroff et al. (7). The FWHM for this transition is $3 \mathrm{eV}$ compared to approximately $4 \mathrm{eV}$ reported for the mixed sulfide/disulfide phase on GaAs (7), arguing against the possibility of multiple oxidation states. The positions of the $S(2 p)$ and $S\left(K L_{2}, 3 L_{2}, 3\right)$ transitions argue 
strongly in favor of sulfur existing as a surface sulfide where the oxidative shift for the $\operatorname{As}\left(2 p_{3} / 2\right)$ is more consistent with the mixed sulfide/disulide response (7). Sulfur identification based on the comparison of a calculated Auger parameter from these data and values reported for metal sulfides is difficult because of differences in a surface species and a solid phase species (23). Reference experiments are currently underway to resolve identification. In either case, the sulfur ring is dissociated in proximity to the surface and reactive $\mathrm{S}$ or $\mathrm{S}_{2}$ radicals are responsible for the formation of an anionic form of sulfur bound to both As and Ga.

Residual carbon is detected on photosulfided surfaces regardless of the initial cleaning process. It appears that the presence of carbon is not necessarily detrimental to the resulting electronic surface properties as indicated by the PL response. Residual carbon and oxygen may preclude observation of good LEED patterns from the photosulfided surfaces.

We have not observed a direct linear relationship between PL intensity increases and the ratio between oxygen and sulfur on the surface. It is possible that the non-linear PL response is due to energetic heterogeneity of the surface. A number of different reaction sites of varying energy may exist on these surfaces; one would expect that energetically different states would contribute differently to the total nonradiative recombination probability. The greatest improvements in surface electronic properties will result from effective passivation of all these sites.

\section{Summary:}

Ultraviolet photosulfidation of $111-\mathrm{V}$ compound semiconductor surfaces is a promising new approach to surface electronic passivation. Because oxygen does not appear to be displaced from the surface by photoactivated sulfur, the optimum degree of 
passivation requires effective techniques for oxide removal and for prevention of reoxidation. The amount of residual oxygen is largely determined by oxygen re-adsorption during the interval between cleaning and photosulfidation. Achieving an oxide free surface will not be a problem in vacuum-integrated environments, but careful attention to oxide removal and post-removal sample handing is necessary for photosulfidation to produce the maximum electronic benefits. Despite this restriction, photosulfidation still passivates the surface of GaAs as well as or better than previous wet $\left(\mathrm{NH}_{4}\right)_{2} \mathrm{~S}$ or dry $\mathrm{H}_{2} \mathrm{~S}$ processes.

\section{Acknowledgements:}

The authors wish to acknowledge J.L. Dishman for technical assistance. This work was performed at Sandia National Laboratories and supported by the U.S. Department of Energy under Contract No. DE-AC04-76DP00789.

\section{Figures:}

Fig. 1: Comparison of normalized PL intensities of photosulfided n-GaAs (100) $\left(6.9 \times 10^{16} / \mathrm{cm}^{3}\right.$ ) after 5 different oxide removal protocols (native oxide surface $=1$ ). For $\mathrm{HCl} /$ ethanol in $\mathrm{N}_{2}$ bag, a) without and b) with additional $\mathrm{N}_{2}$ flow. $\left(\mathrm{NH}_{4}\right)_{2} \mathrm{~S}$ dip included for comparison.

Fig. 2: XPS $\operatorname{As}(2 \mathrm{p} 3 / 2)$ spectra for the native oxide on $\operatorname{GaAs}(100)$ and after etching with 1:20 $\mathrm{NH}_{4} \mathrm{OH} / \mathrm{H}_{2} \mathrm{O}$ and $1: 10 \mathrm{HCl} /$ ethanol.

Fig. 3: XPS As(2p3/2) spectra for UV photolytic deposition of sulfur on $\operatorname{GaAs}(100)$ etched with $1: 20 \mathrm{NH}_{4} \mathrm{OH} / \mathrm{H}_{2} \mathrm{O}$ and $1: 10 \mathrm{HCl} /$ ethanol 
Fig. 4: XPS $S(2 p) / G a(3 s)$ and XAES $S\left(K_{2}, 3 L_{2,3}\right)$ spectra for UV photolytic deposition of sulfur on $\mathrm{GaAs}(100)$ etched with $1: 20 \mathrm{NH}_{4} \mathrm{OH} / \mathrm{H}_{2} \mathrm{O}$ and $1: 10 \mathrm{HCl} /$ ethanol.

\section{References:}

1. W.E. Spicer, N. Newman, C.J. Spindt, Z. Liliental-Weber, and E.R. Weber. J. Vac. Sci. Technol. A8, 2084 (1990).

2. E. Yablonovitch, C.J. Sandroff, R. Bhat, and T. Gmitter, Appl. Phys. Lett. 51, 439 (1987).

3. J.-F. Fan, H. Oigawa, and Y. Nannichi, Jap. J. Appl. Phys. 27, L1331 (1 188).

4. H.H. Lee, R.J. Racicot, and S.H. Lee, Appl. Phys. Lett. 54, 724 (1989).

5. K.C. Hwang and S.S. Li, J. Appl. Phys. 67, 2162 (1990).

6. S. Weiguo, Appl. Phys. A 52, 75 (1991).

7. C.J. Sandroff, M.S Hedge, and C.C.Chang, J.Vac. Sci.Technol. B7, 841 (1989).

8. H. Sugahara, M. Oshima, R. Klauser, H. Oigawa, and Y.Nannichi, Surf. Sci. 242, 335 (1991).

9. T. Tiedje, K.M. Colbow, D. Rogers, Z. Fu, and W.Eberhardt, J. Vac. Sci. Technol. B7, 837 (1989).

10. E. Yablonovitch, T.J. Gmitter, and B.G. Bagley, Appl. Phys. Lett. 57, 2241 (1990).

10: J.S. Herman and F.L. Terry, Jr., Appl. Phys. Lett. 60, 716 (1992).

11. J. Chevallier, W.C. Dautremont-Smith, C.W. Tu, and S.J. Pearton, Appl. Phys. Lett. 47, $108(1985)$.

12. S.J. Pearton, J.M. Kuo, W.S. Hobson, J. Lopata, F. Ren, A. Katz, and M. Geva, Appl. Phys. Lett. 59, 2703 (1991).

13. H. Oigawa, Fan, Nannichi, Ando, Saiki, and Koma, Jap. J. Appl. Phys. 28, L340 (1989). 
14. H. Oigawa, J.-F. Fan, Y. Nannichi, H. Sugahara, and M. Oshima, Jap. J. Appl. Phys. 30, L322 (1991).

15. C.I.H. Ashby, K.R. Zavadil, A.J. Howard, and G.E. Hammons, submitted to Applied Physics Letters.

16. A.Roth, "Vacu m Technology", North-Holland Publishing Co., Amsterdam, 1976, p155.

17. J.E. Baer and M. Carmack, J. Am. Chem. Soc. 71, 1215 (1949).

18. R.P. Vasquez, B.F. Lewis, and F.J. Grunthaner, J. Vac. Sci. Technol. B1, 791 (1983)

19. J.H. Scofield, J. Electron. Spectrosc. Relat. Phenom., 8, 129 (1976).

20. X.-S. Wang, K.W. Self, R. Maboudian, C. Huang, V. Bressler-Hill, and W.H.

Weinberg, J. Vac. Sci. Technol., A 11(4), 1089 (1993).

21. H.J. Yoon, M.H. Choi, and I.S. Park, J. Electrochem. Soc. 139, 3229 (1992).

22. Z.H. Lu, M.J. Graham, X.H. Feng, and B.X Yang, Appl. Phys. Lett., 62(23), 2732 (1993).

23. NIST library: XPS data base 


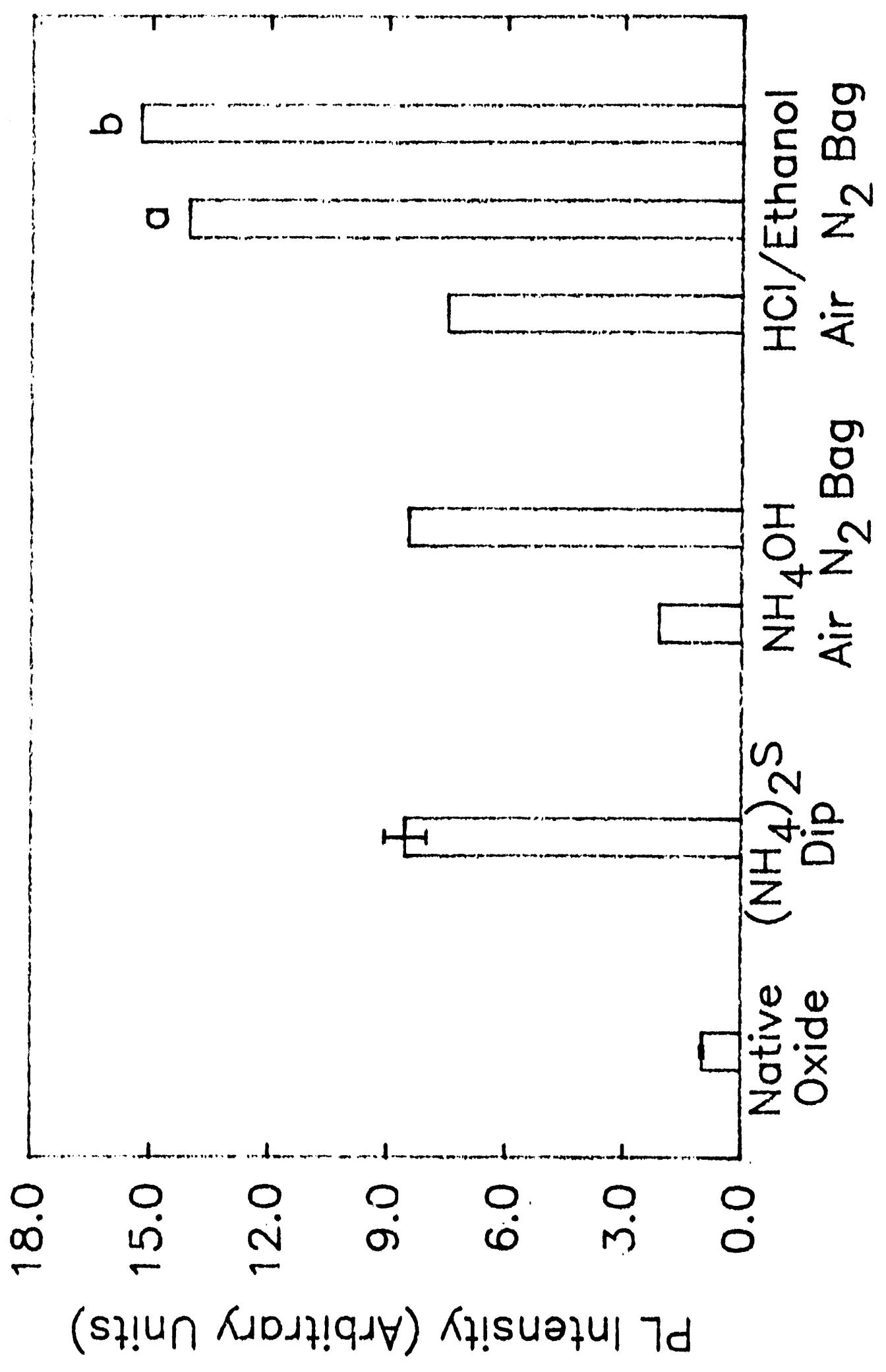

Figure 1

Zavadil et al. 


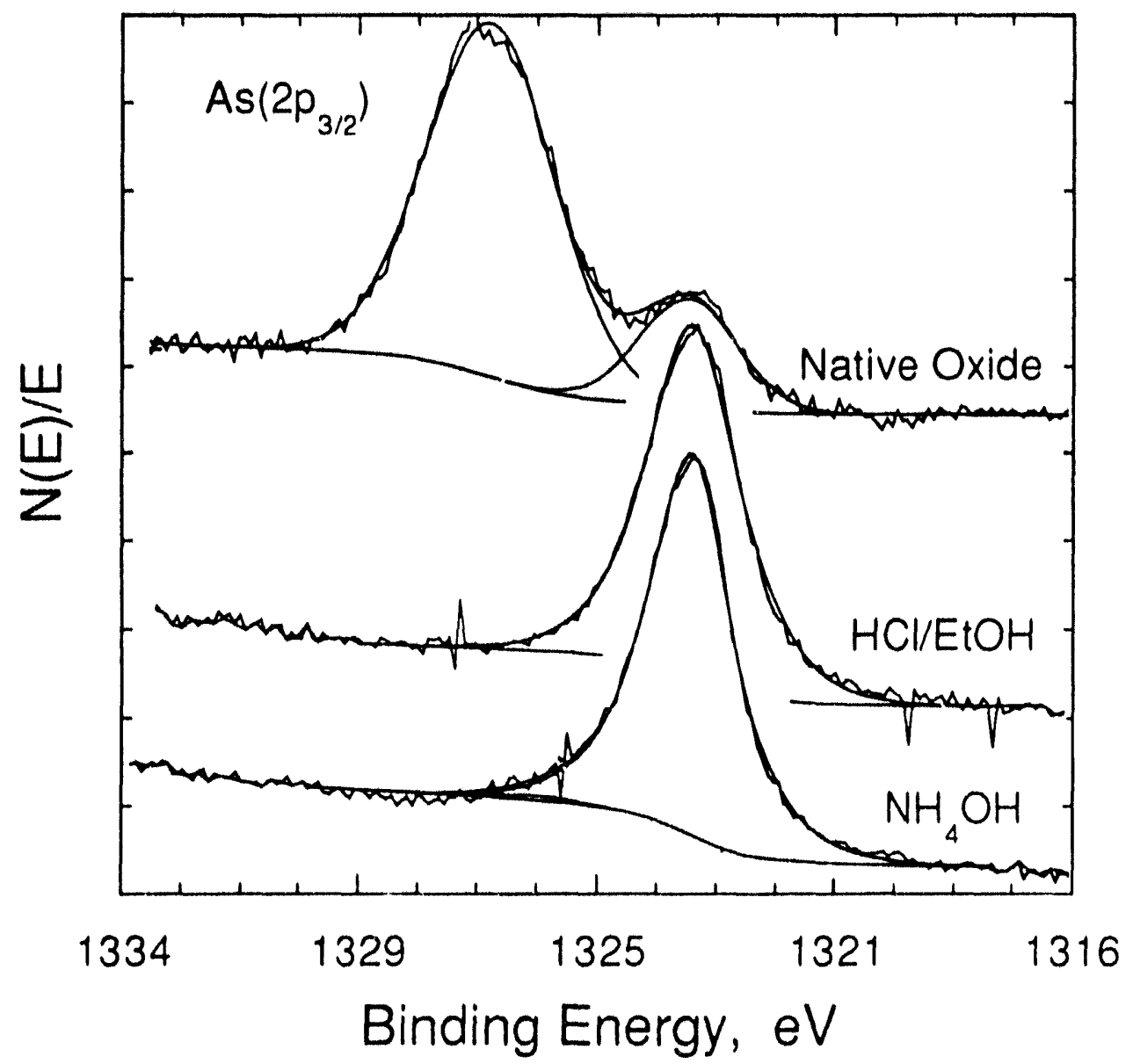

Figure 2

Zavadil et al. 


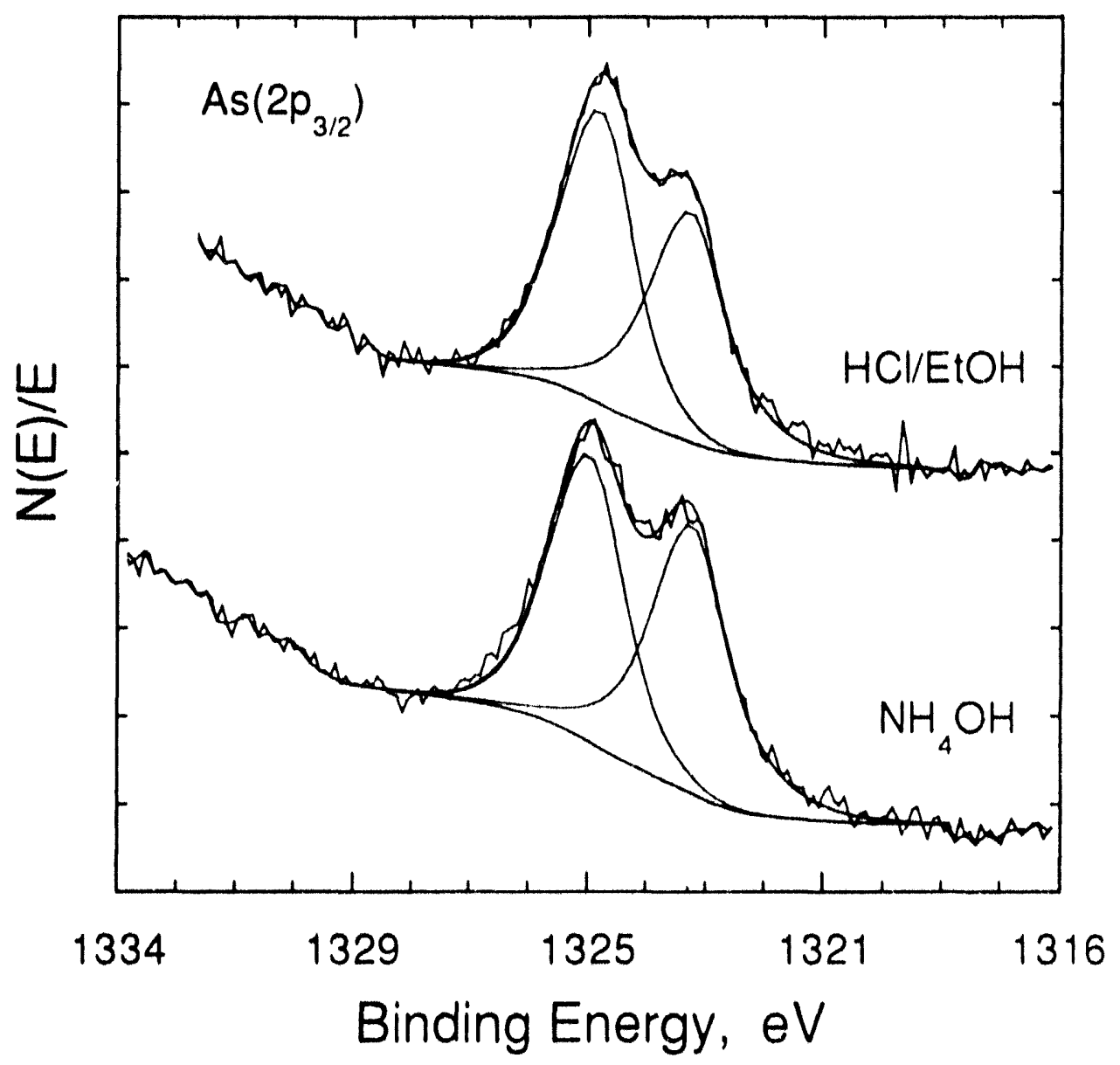

Figure 3

Zavadil et al. 


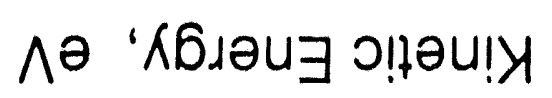

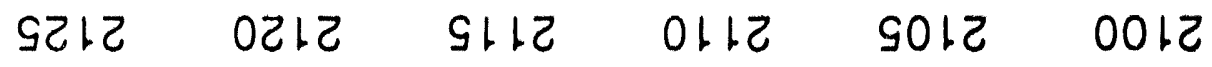
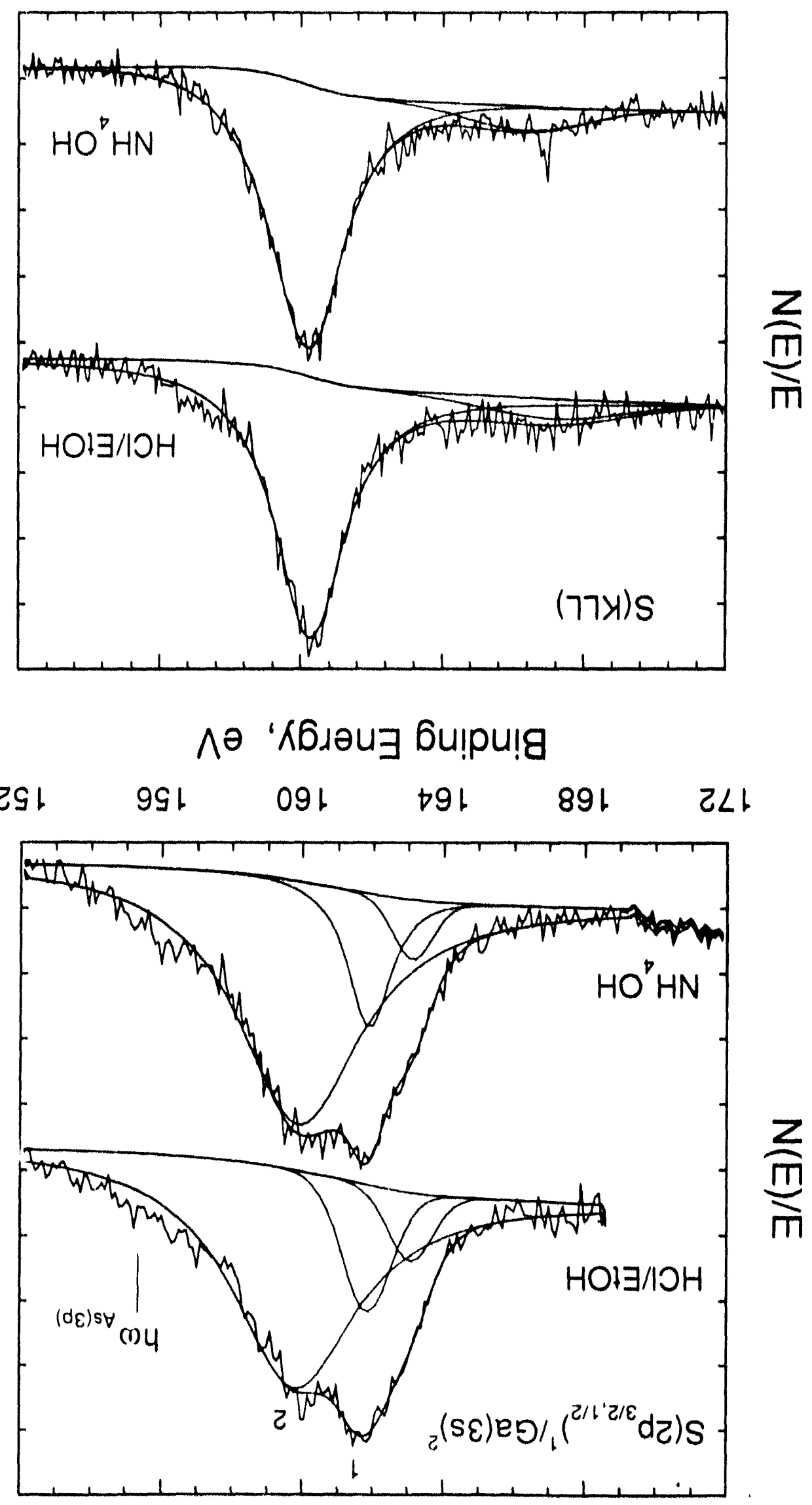

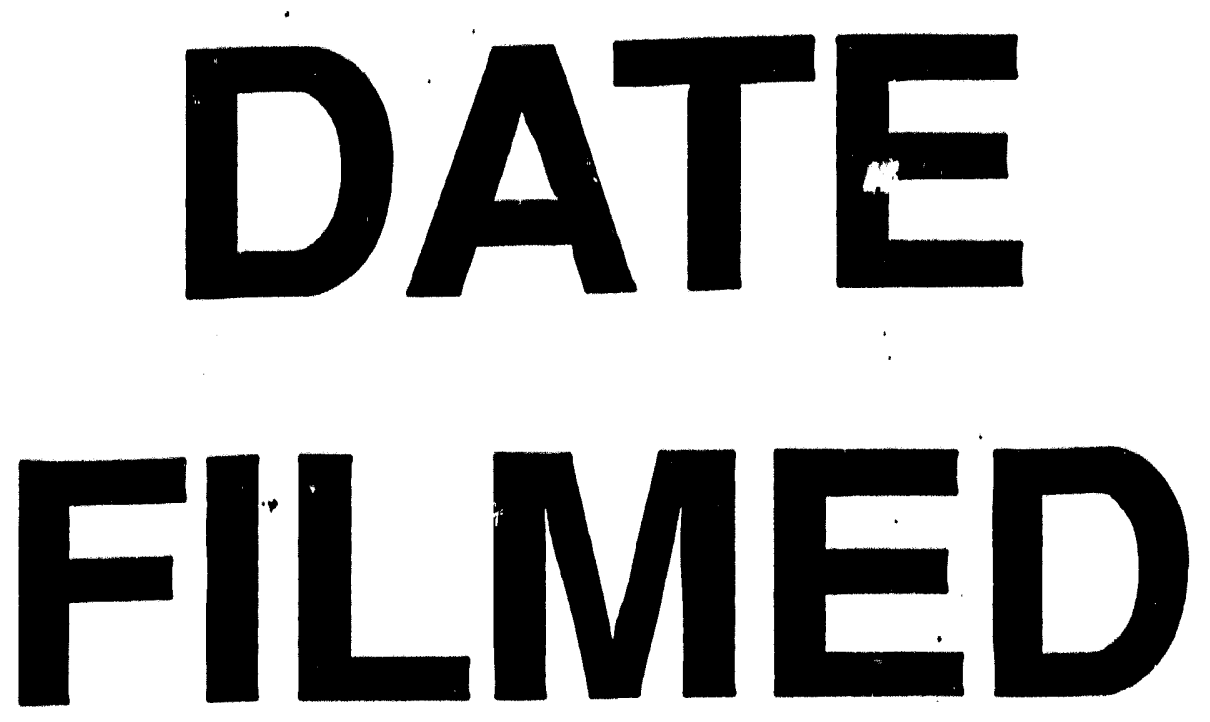

$12 / 8 / 93$
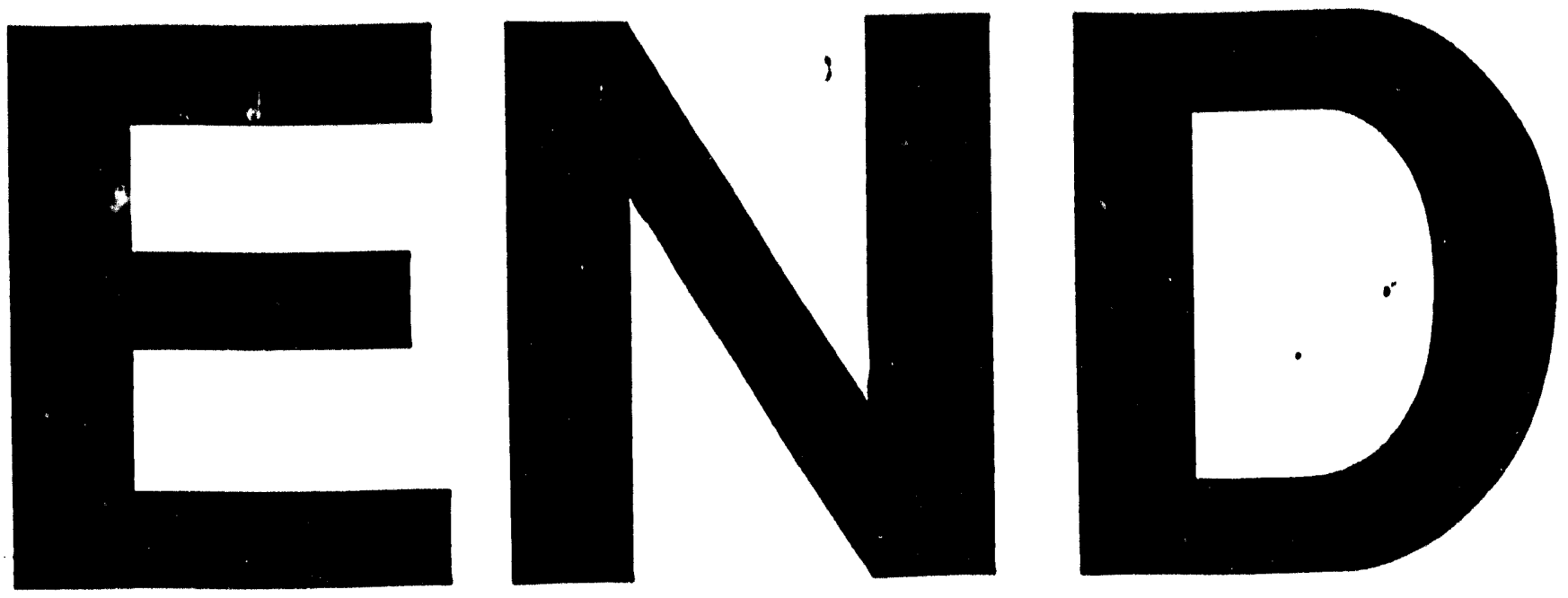
